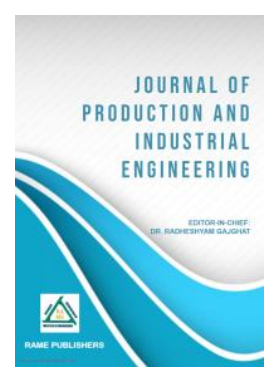

Samarth D. Patil

patilsamarth8@gmail.com

Jamia Hamdard, M. Tech. Research Scholar, Department of Food Technology, Delhi, India

\title{
Blending of Kiwi Guava Mint for preparation of Cordial
}

Abstract-Cordial is a sort of non-alcoholic drink that contains 25\% fruit juice or pulp and has a TSS of 40-50\%. It also contains $1 \%$ acid and 350ppm sulphur dioxide or 600ppm sodium benzoate, which are required for preservation. It is a form of crush that is diluted with water before being served. Kiwi and guava are high in nutrients and have numerous health advantages. Following the preparation, organoleptic examination was performed to determine acceptability.

Keywords - Kiwifruit, Handrefractometer, Sensory analysis, formulation, bioactive Compounds, pasteurization, protocol, hedonic scale.

\section{INTRODUCTION}

Fruits and vegetables are vital components of the diet because they include considerable amounts of nutrients, particularly vitamins, carbohydrates, minerals, and fibre. As a result of the combined action of oxygen radical scavengers like carotene and ascorbic acid with the support of calcium and dietary fibres, the habit of eating fruits and vegetables can help to reduce the risk of cancer, heart disease, stress, and ageing.

Ready-to-drink beverages are packaged and ready for drinking. Fruit-based beverages are especially popular when served chilled, especially in the summer. These are both delicious and nutritious, as they contain the goodness of fresh fruit. These spices, in addition to their palatable qualities, contain medicinal and therapeutic capabilities that have a direct impact on human health due to their numerous functional functions. Squash beverages are made in a variety of ways using citrus fruit, sugar, and water. Fruit beverages can also be made from pineapple, orange, lime, litchi, passion fruit, and other locally grown fruits.

Technical Article - Peer Reviewed

Published online - 31 December 2021

\section{(C) 2021 RAME Publishers}

This is an open access article under the CC BY 4.0 International License https://creativecommons.org/licenses/by/4.0/

Cite this article - Samarth D. Patil, "Blending of Kiwi Guava Mint for preparation of Cordial", Journal of Production and Industrial Engineering, RAME Publishers, vol. 2, issue 2, pp. 31-35, 2021. https://doi.org/10.26706/jpie.2.2.20211201

\section{A. KIWI}

Vitamins C, E, and A are abundant in kiwifruit. It contains dietary fibre as well as minerals such as potassium, phosphorus, magnesium, and copper. It has the unique ability to remove excess salt from the body, which is beneficial to the normal person who consumes too much sodium in his everyday life. In addition, the green fruit is high in antioxidants and digestive enzymes. Kiwifruit is supposed to improve respiratory health and alleviate nighttime coughing. It has been revered for its therapeutic virtues since ancient times and is thought to be of Chinese origin. It is currently known as the New Zealand national fruit rather than its previous names, Yang tao or Chinese gooseberry. It apparently made its way to New Zealand via missionaries and became so popular in the country that it began to be cultivated professionally and marketed as 'kiwi' (bearing close resemblance to their national bird).

\section{B. GAUVA}

This tropical fruit, often known as 'Peru,' is widely available. And because they are quite inexpensive as compared to other options, we can all afford them. In the third instalment of our Far Eastern plant series, we look at Guava, also known as Psidium guajava. In folk medicine, preparations of the roots, bark, and leaves are used to cure gastroenteritis. Guavas are marketed at various stages of ripeness. However, they should be eaten within one to two 
days of ripening. You will be astounded by the health benefits that this fruit provides that we take for granted.

\section{MINT}

Mint, often known as mentha, is a genus or group of 15 to 20 plant species that includes peppermint and spearmint. Menthol piperita, also known as mint oil, is widely used in cookies, toothpaste, gum, sweets, and beauty products, while the leaves, whether fresh or dried, are utilised in teas and food. Herbs are plants valued for their medicinal and aromatic properties, and they are widely planted and harvested for their unique properties.

\section{KEY DETAILS}

\section{A. Objectives}

1. To develop a nutritious squash drink from Kiwi and Guava.

2. To study the physical aspects of the squash like colour, taste, appearance.

3. To evaluate the quality of nutritious squash drink through sensory characteristics.

4. To evaluate the overall quality of the blended mixture using sensory analysis.

\section{B. Review of literature}

Fruits and vegetables are effective in the treatment of cardiovascular disease. The antioxidants and other components of fruits and vegetables explain their positive effects. These nutrients may act individually or together to protect lipoproteins and vascular cells against oxidation, or by other mechanisms such as lowering plasma lipid levels (LDL cholesterol, triglycerides), and platelet aggregation response. The kiwi fruit, which is abundant in vitamin $\mathrm{C}$, vitamin E, and polyphenols, may be advantageous in cardiovascular disease; however, little is known regarding its cardiac preventive benefits. Platelets have a role in the development of atherosclerotic disease, and drugs that limit platelet activity reduce the incidence and severity of illness.
According to Kawaiietal (2000), the main reason for its cultivation is for its alkaloids, which have anticancer activities, and the antibacterial potential in crude extracts of different parts of Lemon (viz., leaves, stem, root, and flower) against clinically significant bacterial strains has been reported.

Aronson, Aronson (2001): Flavonoids are commonly found in glycosylated forms in plants, and the sugar moiety plays a significant role in influencing their bioavailability. Citrus fruits, in addition to fibre, contain bioactive substances such as polyphenols, the most significant of which is vitamin $\mathrm{C}$ (or ascorbic acid), and they can prevent and cure vitamin $\mathrm{C}$ deficiency, which is the cause of scurvy. The existing literature on the many elements of orange-beetroot RTS formulation, development, nutritional, sensory, and storage studies have been reviewed as noted below.

According to Sohnet al. (2004), flavonoids can serve as direct antioxidants and free radical scavengers, as well as modify enzyme activity and suppress cell proliferation (Duthie and Crozier, 2000). They appear to perform a defensive role in plants, preventing pathogens such as bacteria, fungus, and viruses from entering.

\section{Raw materials and Equipment's}

Kiwi, Guava, Mint, Sugar are the basic things needed along with that various instrument used were knife, plates, peeler, mixture, strainer, weighting balance, hand refractometer.

\section{Packaging}

Packaging is the process of covering or wrapping things for transportation, storage, disposal, and use. Packaging safeguards food against mechanical damage such as mechanical stress, vibration, compression, temperature, and electronic discharge. Packaging is also effective for safeguarding food from chemical changes that are detrimental to the end product's quality. It does not transfer oxygen, water vapour, or other gases; instead, it serves to extend the shelf life of the product. The Kiwi-Gauva mint 
squash came in PET bottles with a cap. PET and glass bottles are the most often used packaging materials for RTS beverages.

\section{E. Formulation}

Many permutations and combinations with food items are formed by combining basic components in particular quantities in an organised fashion, and research on the outcome of these diverse product formulations aids in product creation. Three samples were created by altering the amounts of Kiwi fruit and Guava so that the final product's qualities could be easily identified. The formulation is shown in the table below.

TABLE 1

SAMPLE FORMULATION

\begin{tabular}{|c|c|c|c|c|}
\hline Sr. No. & Ingredients & Sample A & Sample B & Sample C \\
\hline 1. & Kiwi pulp & $15 \mathrm{gm}$ & $7 \mathrm{gm}$ & $18 \mathrm{gm}$ \\
\hline 2. & Guava pulp & $10 \mathrm{gm}$ & $18 \mathrm{gm}$ & $7 \mathrm{gm}$ \\
\hline 3. & Mint & $3 \mathrm{ml}$ & $3 \mathrm{ml}$ & $3 \mathrm{ml}$ \\
\hline 4. & Sugar & $38 \mathrm{gm}$ & $38 \mathrm{gm}$ & $38 \mathrm{gm}$ \\
\hline 5. & Citric acid & $0.3 \mathrm{gm}$ & $0.3 \mathrm{gm}$ & $0.3 \mathrm{gm}$ \\
\hline 6. & Sodium & $0.01 \mathrm{gm}$ & $0.01 \mathrm{gm}$ & $0.01 \mathrm{gm}$ \\
\hline 7. & Benzoate & & & $34 \mathrm{ml}$ \\
\hline
\end{tabular}

\section{F. Preparation method}

1. Selection of raw material: good quality kiwi and guava were purchased from market and blended together in the preparation of Kiwi-Guava mint squash.

2. Washing: Kiwi fruit, guava fruit and mint are washed to remove dirt, dust and other contaminant on the surface.

3. Peeling: After washing of fruits and mint all the roots and fruits are peeled out.

4. Cutting: After peeling the fruits are cut in small size required for the juice extraction by grinder.

5. Pulp extraction: Pulp extraction was done by using mixer. All juices of ingredient are extracting separately and store. Mint water were done by adding mint to hot water and mixing with sugar syrup. Kiwi guava pulp was extracted.
6. Mixing: After pulp extraction, above prepared KiwiGuava pulp (25\%) mix with sugar syrup (75\%) (Upto 40 Brix) and preparation of Squash was done.

7. Pasteurization: Squash is pasteurized at $800 \mathrm{C}$ for 15 min to remove the contaminants from raw pulp.

8. Filling and capping: The squash was filled in sterile a glass bottles (capacity $200 \mathrm{ml}$ ) and capping

9. Pasteurization: Glass bottles are pasteurized at $850 \mathrm{C}$ for $15-20 \mathrm{sec}$.

10. Labelling: Labelling was done.

11. Storage: Storage in cool and dry place or in refrigeration condition

\section{G. Sensory method}

Protocol for sensory analysis:

Sensory evaluation is a study that helps with examination and measures human responses to the composition of food. e.g., appearance, touch, flavor, texture, color, appearance and taste. Various scales or methods are used for the sensory assessment of product. For sensory analysis of my squash three samples were prepared and sensory was done with the help of semitrained panel of 9 members. For sensory analysis of my squash, hedonic scale was used for better result. It is 50 most widely used scale for measuring food acceptability is the 9-point hedonic scale. On this scale rating or marks are given according to acceptability of product. Various parameters are included in this scale for sensory analysis such as color, flavor, texture, taste, appearance, overall acceptability, etc.

Sensory evaluation can be drawn to:

- Compare similarities/differences in a range of products.

- Assess a range of existing food products.

- Examine food samples for improvements.

- Gauge reactions to a product, e.g. acceptable or unacceptable.

- Certain specific characteristics of an ingredient or food product. 
- Check whether a final dish/food product meets its original specification.

- Provide objective and subjective feedback data to enable informed decisions to be made.

ACCEPTANCE: Sample B was excepted by the panel. Finally accepted product was selected.

\section{H. Results of sensory analysis}

With the help of this hedonic scale sensory analysis results are obtained. These results are shown below:

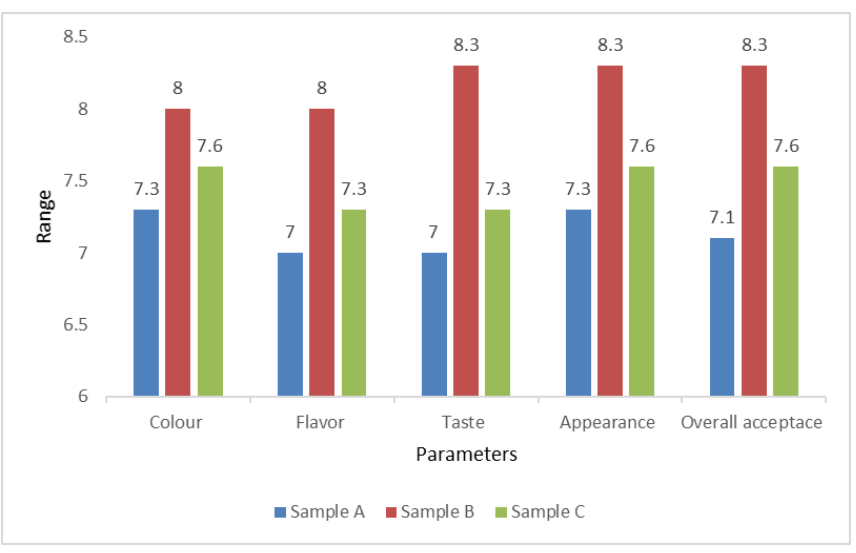

Figure 1. Average sensory analysis data

\section{CONCLUSIONS}

A vast variety of squash drinks are now available on the market. Consumption of healthy and nutritious food is required to avoid such a hazardous health problem.

They were utilised in the manufacture of squash drink because they include a combination of minerals, vitamins, antioxidants, and bioactive components found in kiwi and guava. Healthy eating isn't just about tight dietary restrictions; it's also about not being unnaturally thin or depriving yourself of foods you enjoy.

Foods containing bioactive compounds can also give numerous health benefits, such as aiding in weight maintenance and lowering the risk of diabetes, cancer, and heart disease. The successful integration of Kiwi, Guava, and Mint in such squash beverages was investigated.

\section{REFERENCE}

[1] Keith S., "Kiwifruit: Overview of Potential Health Benefits", Nutrition Today, May/June 2012, Volume :47 Number 3, page $133-147$.

https://www.doi.org/10.1097/NT.0b013e31825744bc

[2] M. Mohanapriya, Dr. Lalitha Ramaswamy, Dr. R. Rajendran, "Health and Medicinal Properties of Lemon (Citrus Limonum)", International Journal Of Ayurvedic And Herbal Medicine, page no.1096-1098, Volume 3, issue 1, 2013.

[3] Shrivastavaalankar, "A review on peppermint oil", Asian Journal of Pharmaceutical and Clinical Research, Volume 2, Issue 2, April- June 2009.

[4] Udemezue O.O, Ukoha U., Ezejindu D.N, Okafor J. I, and Obilor AD, "The Effects of Leaf Extract of Guava on the Liver Enzymes of Adult Wistar Rats”, International Journal of Scientific and Research Publications, Volume 4, Issue 8, August 2014.

[5] Aflatuni, Abbas, "The yield and essential oil content of mint (Mentha ssp.) in Northern Ostrobothnia”, Oulu University Press, Oulu 2005, June 10th, 2005.

[6] Barbalho S.M., "Psidium Guajava (Guava): A Plant of Multipurpose Medicinal Applications, Medicinal \& Aromatic Plants” Medicinal \& Aromatic Plants, Volume 1, 2012. https://www.doi.org/10.4172/2167-0412.1000104

[7] Neeta Chaudhary, Shalini Tripathi, "A Review on Multipurpose Plant: Psidium Guajava", International Journal of Pharmacognosy and Phytochemical Research, Volume 6, issue 1, 118-121, 2014.

[8] Chetia J, Upadhyaya S., Boraand D.K, and Saikia L.L.R., "Phenolic content, Anti-oxidant and antimicrobial activity and nutritive value of young twig of psidium guagaalinn. From Dibrugarh, Assam", International Journal of Pharmacy and Pharmaceutical Science, ISSN 0975-1491, 2014.

[9] Duttaroy A.K and AudJørgensen (2004), "Effects of kiwi fruit consumption on platelet Aggregation and plasma lipids in healthy human Volunteers", Platelets, Volume 15, Issue 5, 2004, pp 287-292. https://doi.org/10.1080/09537100410001710290

[10] Francesco Forastiere et. al., "Consumption of fresh fruit rich in vitamin $\mathrm{C}$ and wheezing symptoms in children”, Thorax, Volume 55, 2000, pp 283-288. https://www.doi.org/10.1136/thorax.55.4.283 
[11] Joseph B., "Review on nutritional, medicinal and pharmacological properties of guava (psidium guajava linn.)", International Journal of Pharma and Bio Sciences, volume 2, issue 1, pp. 53-69, 2011.

[12] Julia R. Esch, Jeffrey R. Friend, James K. Kariuki, "Determination of the Vitamin C Content of Conventionally and Organically Grown Fruits by Cyclic Voltammetry", International Journal of Electrochemical Science, Volume 5, 2010, pp. 1464 - 1474.

[13] Kumar A., "Importance for Life 'Psidium guava", International Journal of Research in Pharmaceutical and Biomedical Sciences, Vol. 3, 2012. 